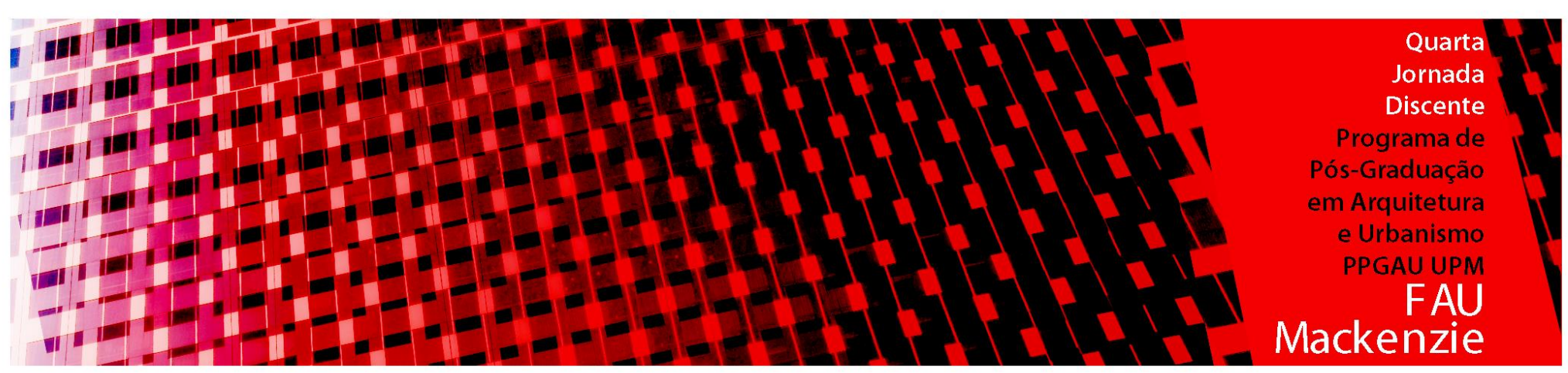

\title{
A Evolução das Legislações e Políticas para Reabilitação de Áreas Contaminadas na Cidade de São Paulo
}

\section{Evolution of Legislation and Policies for the Redevelopment of Contaminated Sites in São Paulo}

\author{
Nathalia da Mata ${ }^{1}$, Gilda Collet Bruna ${ }^{2}$ \\ ${ }^{1}$ Universidade Presbiteriana Mackenzie, São Paulo, Brasil, arq.damata@ gmail.com \\ ${ }^{2}$ Professora Doutora, Universidade Presbiteriana Mackenzie, São Paulo, Brasil, \\ gildacbruna@gmail.com
}




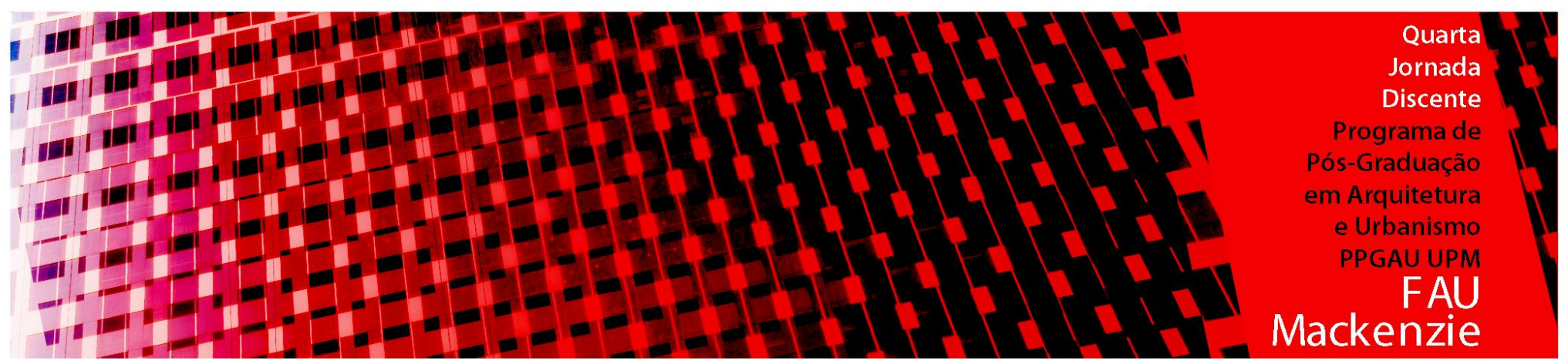

\title{
RESUMO
}

Ao longo da história, o solo tem sido predominantemente abordado como receptor inesgotável de resíduos, em especial a partir da Revolução Industrial que, de diferentes maneiras entre os países, desencadeou a emissão descontrolada de poluentes no solo, gerando o que se chama de passivo ambiental. Nas últimas décadas, tal visão tem sido alterada a fim de entender o solo como um recurso limitado, levando a preocupação com as consequências da poluição no solo. A questão das áreas contaminadas encontra, em especial, um empecilho no Brasil, país de dimensões continentais. Isto porque, diferentemente de países europeus, não existe uma preocupação com a finitude dos recursos do solo (SPÍNOLA, 2011). O Estado de São Paulo que concentra a maior parte das áreas contaminadas do país, teve seu desenvolvimento industrial a partir da década de 1950 caracterizado pelas ocupações do solo em sua maior parte sem restrições ambientais que evitassem a formação de um passivo ambiental. Assim sendo, este artigo focaliza a evolução dos instrumentos legais, objetivando formular uma compreensão do desenvolvimento das políticas que estimulam a reabilitação de áreas contaminadas, considerando-as ao longo do tempo, no Brasil, no Estado de São Paulo, e finalmente na cidade de São Paulo. Para tanto, fez-se uso da estrutura de três estágios apresentada por Adams, De Sousa e Tiesdell (2010) sobre a maturidade de políticas para a reabilitação de áreas contaminadas.

Palavras-chave: Áreas contaminadas, Sustentabilidade, Planejamento Urbano, Legislações, Reabilitação.

\begin{abstract}
Throughout the history, soil has been considered an inexhaustible resource, especially since the Industrial Revolution when the pollutant emission has started in a non-controlled way, differing among the countries, but always creating an environmental liability. In the last decades, such a vision has been altered aiming to understand soil as limited resource, taking into consideration the consequences of soil contamination. The matter of contaminated sites finds specific difficulties in Brazil, a country of continental dimensions. Differently from European countries, in Brazil there is no strong concern about the finitude of soil resources (SPÍNOLA, 2011).

The state of São Paulo, which concentrates most of the contaminated sites in the country, had its industrial development in the 1950's, characterized by the lack of legal environmental restrictions that could avoid the development of liability. Therefore, this study focuses on the evolution of legal tools, aiming a better understating of the development of policies that facilitate the redevelopment of contaminated sites throughout the time in Brazil, in the state of São Paulo and in the capital. For that, the study makes use of the three stages structure proposed by Adams, De Sousa e Tiesdell (2010) about the maturity of policies for the redevelopment of contaminated sites.
\end{abstract}

Key-words: Contaminated sites, Sustainability, Urban Planning, Policies, Redevelopment. 


\section{INTRODUÇÃ̃O}

Ao longo da história, o solo tem sido predominantemente abordado como receptor inesgotável de resíduos, em especial a partir da Revolução Industrial que, de diferentes maneiras entre os países, desencadeou a emissão descontrolada de poluentes no solo, gerando o que se chama de passivo ambiental (MARKER in SPÍNOLA, 2011). No caso do Brasil, mais especificamente do Estado de São Paulo que concentra a maior parte das áreas contaminadas do país, as ocupações do solo ocorreram durante as décadas de 1950 e 1960 em sua maior parte sem restrições ambientais que evitassem a formação de passivos.

Assim como o solo, a utilização de recursos naturais passou a ser revisada após o episódio histórico da Crise do Petróleo na década de 1970, que desencadeou diversos movimentos que reivindicavam usos mais sustentáveis dos recursos naturais. Em 1987, durante a Conferência das Nações Unidas em Genebra, foi elaborado o relatório "Our Common Future" ("Nosso Futuro Comum") que define o desenvolvimento sustentável como aquele que permite conciliar as necessidades das populações atuais sem comprometer a qualidade de vida das futuras gerações (UNITED NATIONS, 1987).

Paralelamente a esses acontecimentos, acontecia no mundo um processo que desencadearia uma nova temática para as discussões sobre sustentabilidade: a desindustrialização de regiões tipicamente industriais, em decorrência da reestruturação econômica mundial e do emprego de novas tecnologias de produção (CAMPOS NETO, SOMEKH; 2005). Tal processo fez com terrenos de uso industrial, caracterizados pelos grandes galpões próximos a importantes ferrovias e rodovias de centros urbanos, fossem esvaziados, deixando o passivo ambiental formado nas décadas anteriores, como no exemplo da figura 1.

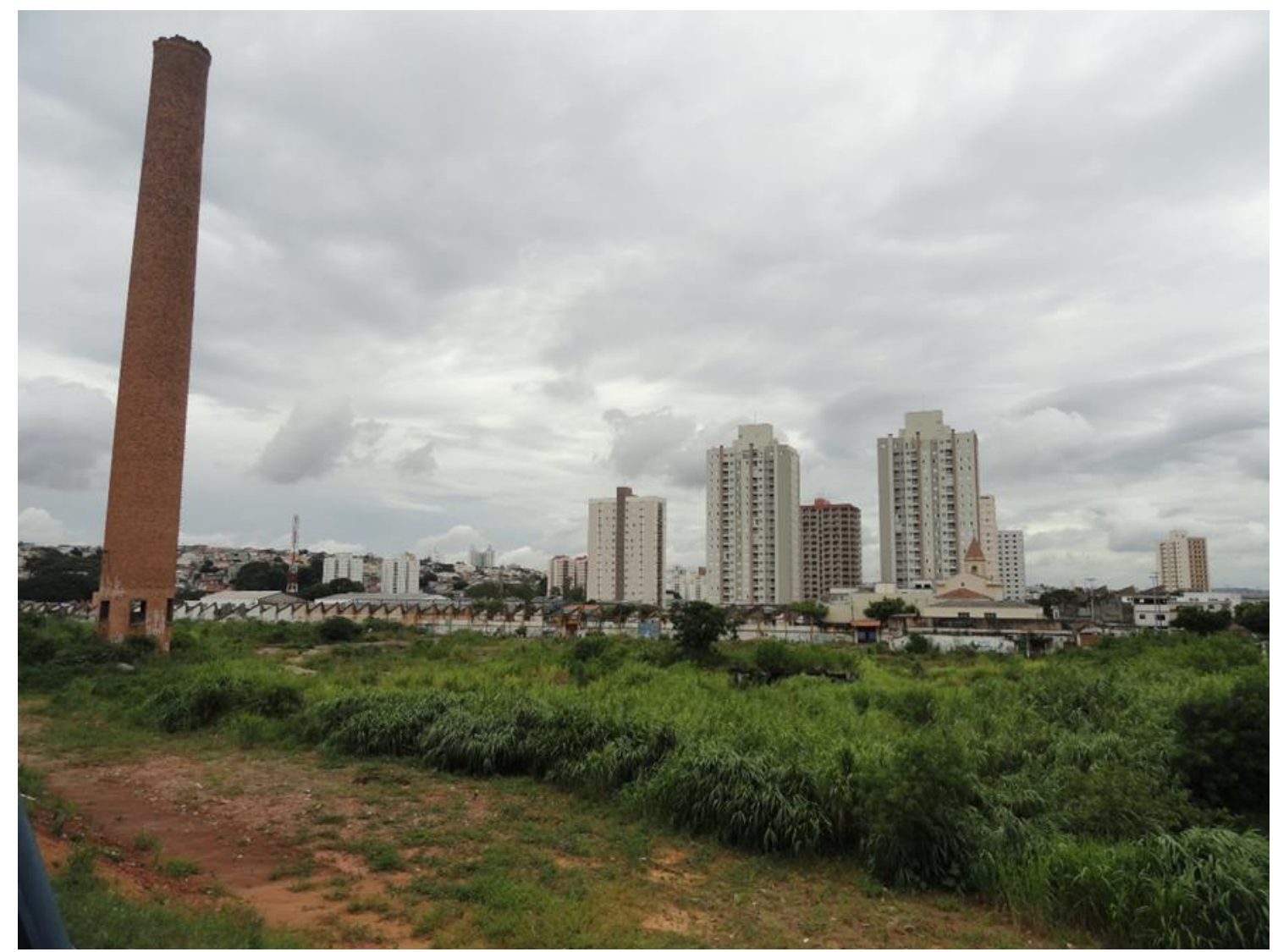

Figura 1: Terreno industrial esvaziado e contaminado na divisa de São Paulo e São Caetano do Sul. Fonte: DA MATA, 2017. 
Dada a gravidade do problema, não tardou a surgir um caso grave de contaminação: ainda na década de 1970, o caso de Love Canal, um aterro com resíduos industriais em um trecho do Rio Niágara nos Estados Unidos. O caso chamou a atenção da mídia pois a região, que havia se desenvolvido e se tornado um bairro de classe média, começou a apresentar casos entre os habitantes que se queixavam de problemas de saúde ligados a contaminação do solo e da água. Diversas famílias precisaram ser evacuadas do local (SÂNCHEZ, 2001).

Além do uso industrial, há outras atividades potencialmente poluidoras que merecem atenção: do total de áreas cadastradas como contaminadas hoje no Estado de São Paulo, a maioria são ou foram postos de combustível, como demonstrado na tabela 1 abaixo:

Tabela 1: Áreas cadastradas na CETESB distribuídas em regiões do Estado de São Paulo.

\begin{tabular}{ccccccc}
\hline Região & $\begin{array}{c}\text { Atividade } \\
\text { Comercial }\end{array}$ & $\begin{array}{c}\text { Atividade } \\
\text { Industrial }\end{array}$ & Resíduos & $\begin{array}{c}\text { Postos de } \\
\text { Combustível }\end{array}$ & $\begin{array}{c}\text { Outras } \\
\text { atividades }\end{array}$ & Total \\
\hline São Paulo & 110 & 389 & 57 & 1.579 & 13 & 2.148 \\
RMSP - & 56 & 282 & 34 & 649 & 12 & 1.033 \\
outros & & & & &
\end{tabular}

Fonte: MANNA et al, 2018, p. 15.

Além do risco à segurança e à saúde humana e do ambiente, áreas contaminadas tornaram-se uma questão bastante relevante no planejamento urbano devido à desvalorização imobiliária do terreno e de seu entorno (SÁCHEZ, 2004). Isso porque, por conta do passivo ambiental derivado das atividades anteriores e ao alto custo da remediação necessária para reabilitar o solo para novos usos, investidores costumam evitar tais terrenos. Frequentemente as áreas contaminadas permanecem vazias por longo tempo, não cumprindo sua função social da propriedade (CAIXA ECONÔMICA FEDERAL, 2014). Isso não significa que não exista interesse de mercado em tais terrenos: o fato de se situarem próximas a áreas urbanas consolidadas e com infraestrutura e se constituírem geralmente de grandes lotes, faz com que esses terrenos sejam visados pelo mercado imobiliário para a implantação de empreendimentos.

Levando em consideração o problema das áreas contaminadas e a tendência contemporânea de planejamento urbano visando o desenvolvimento de cidades sustentáveis, é necessário a remediação e reabilitação dessas áreas, não só as recuperando ambientalmente, como afirma Sánchez (2001), mas também promovendo a reinserção destes terrenos no tecido da cidade por meio de instrumento de requalificação urbana, como no exemplo da figura 2.

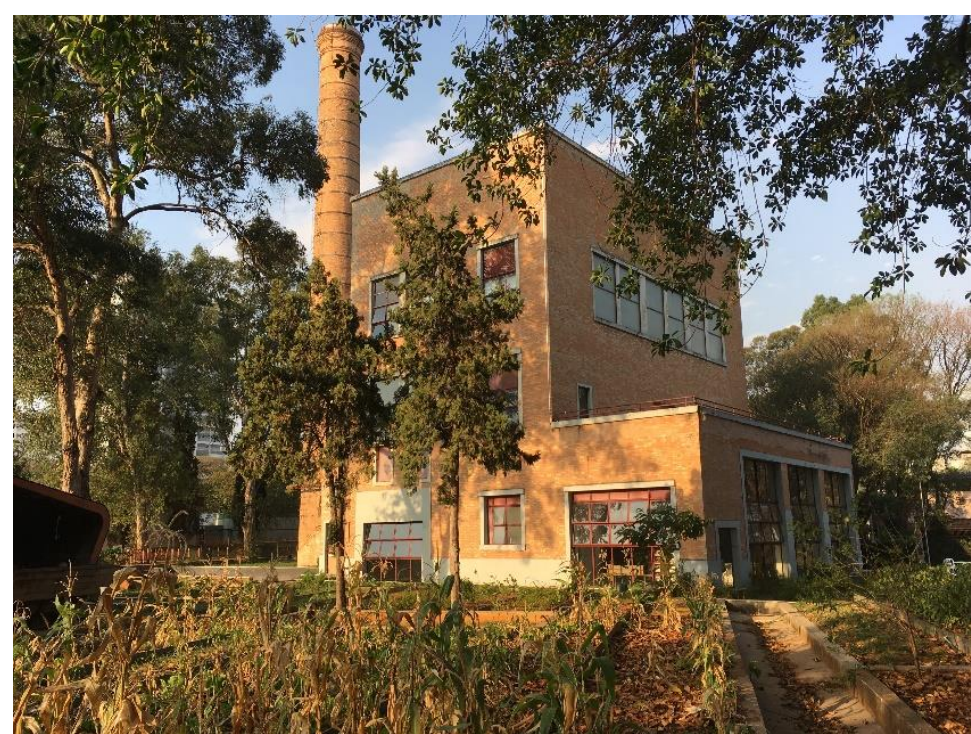

Figura 2: Antiga incineradora reabilitada que hoje abriga a Praça Vitor Civita e o Museu da Sustentabilidade. Fonte: DA MATA, 2018. 
Segundo Adams, de Sousa e Tiesdell (2010), é necessária uma mudança da visão sobre as áreas vagas na cidade: de problemas de planejamento, para oportunidades de desenvolvimento urbano, pautada na maturação das políticas e legislações. Segundo os autores, o processo de desenvolvimento de legislações passa por três estágios: primeiramente, pela compreensão da questão das áreas contaminadas, inclusive passando por sua definição legal e o mapeamento das áreas afetadas; segundo, pelo comprometimento político, pela identificação das maiores dificuldades e pelo estabelecimento das ações necessárias; por fim, pela geração de engajamento do setor privado.

Assim sendo, este artigo focaliza a evolução dos instrumentos legais no Brasil, objetivando formular uma compreensão do desenvolvimento das políticas que estimulam a reabilitação de áreas contaminadas, considerando-as ao longo do tempo, no Brasil, no Estado de São Paulo, e finalmente na cidade de São Paulo.

\section{REFERENCIAL TEÓRICO: LEGISLAÇÕES PARA REABILITAÇÃO DE ÁREAS CONTAMINADAS}

\subsection{Legislações Nacionais}

A questão das áreas contaminadas encontra especial empecilho no Brasil, país de dimensões continentais. Isto porque, diferentemente de países europeus, não existe uma preocupação com a finitude dos recursos do solo (SPÍNOLA, 2011) o que leva a um descaso com o planejamento. Apesar disso, existe um arcabouço legal que permeia a questão das áreas contaminadas, cuja evolução será apresentada a seguir.

\subsubsection{Legislações e Políticas Ambientais}

Pode-se dizer, conforme Spínola, (2011) que até o ano 2009 não era possível contar com políticas federais que tratassem da questão das áreas contaminadas, pois não havia legislação específica sobre o assunto "áreas contaminadas" em escala nacional.

A primeira legislação a tratar indiretamente do tema data de 1981, tendo sido estabelecida pela Lei $\mathrm{n}^{\circ}$ 6.938, trazendo a Política Nacional de Meio Ambiente com suas muitas definiçõos, além de destacar a necessidade de recuperação ambiental. Além disso, trata da racionalização do uso do solo, a fim de controlar o recurso natural do país. Essa legislação de 1981 foi importante também porque criou o CONAMA - Conselho Nacional do Meio Ambiente - um órgão colegiado com participação de grupos de trabalho e assessores e com câmaras técnicas que passa a analisar e aprovar projetos e intervenções para que possam ser levados a efeito.

Mas foi somente após nove anos, que o Decreto $n^{\circ}$ 99.274/1990 veio complementar essa Política, adicionando a necessidade de o Poder Público identificar as áreas degradadas e propor medidas para sua recuperação, embora já em 1988 a Constituição Federal tenha introduzido a obrigação do Poder Público promover ambientes ecologicamente equilibrados. Desse modo, no Art. 225 da Constituição Federal, destaca-se que:

Art. 225. Todos têm direito ao meio ambiente ecologicamente equilibrado, bem de uso comum do povo e essencial à sadia qualidade de vida, impondo-se ao Poder Público e à coletividade o dever de defendê-lo e preservá-lo para as presentes e futuras gerações.

$\S 1^{\circ}$ - Para assegurar a efetividade desse direito, incumbe ao Poder Público: 
(...)

IV - Exigir, na forma da lei, para instalação de obra ou atividade potencialmente causadora de significativa degradação do meio ambiente, estudo prévio de impacto ambiental, a que se dará publicidade;

(...) $\mathrm{e}$

VII - proteger a fauna e a flora, vedadas, na forma da lei, as práticas que coloquem em risco sua função ecológica, provoquem a extinção de espécies ou submetam os animais a crueldade. (...) (BRASIL, 1988, n. p.).

A partir disso, começa a se tornar importante preservar o Meio Ambiente, como se pode depreender da legislação nacional. Entre suas características de cuidado também se destaca a conservação da natureza, que foi alvo da Lei Federal $n^{\circ} 9.985$ do ano 2000, instituindo o Sistema Nacional de Unidades de Conservação da Natureza (SNUC). Além disso, apresenta importantes preocupações com ações em prol da reabilitação de áreas contaminadas, como se observa em seu art. $2^{\circ}$ que em seu inciso XIII que focaliza as áreas degradadas, impondo a recuperação e restauração ambiental:

XIII - recuperação: restituição de um ecossistema ou de uma população silvestre degradada a uma condição não degradada, que pode ser diferente de sua condição original;

XIV - restauração: restituição de um ecossistema ou de uma população silvestre degradada o mais próximo possível da sua condição original;

(BRASIL, 2000, n. p.).

Ainda neste ano 2000, a Resolução CONAMA no 273 estabeleceu que os responsáveis pela contaminação devem remediar o solo para a retirada dos passivos ambientais. Também estabelece a necessidade de haver um plano de encerramento para empreendimentos possivelmente poluentes no momento de sua desativação, deixando assim a área passível de receber novos usos. Estabelecese assim a lógica de responsabilidade do poluidor, conforme o Código Civil de 2002 (lei $\mathrm{n}^{\mathrm{o}}$ 10.406) que obriga o poluidor a pagar o reparo dos danos ambientais, independentemente de sua culpa.

No entanto, foi apenas em 2009 que a Resolução CONAMA n 420, lei federal, voltou-se especificamente para o problema das áreas contaminadas. Tal Resolução estabelece critérios gerais de qualidade de solo, valores de referência que até então só existiam para a qualidade da água e do ar. Sobre critérios de qualidade mais específicos, esta Resolução traz que devem ser estabelecidos pelos órgãos ambientais dos Estados, em até 4 anos após a emissão desta resolução. Além disso, pode-se destacar definições importantes sobre contaminação e remediação, como se vê a seguir:

Art. $6^{\circ}$ Para efeito desta Resolução são adotados os seguintes termos e definições:

(...)

V - Contaminação: presença de substância (s) química (s) no ar, água ou solo, decorrentes de atividades antrópicas, em concentrações tais que restrinjam a utilização desse recurso ambiental para os usos atual ou pretendido, definidas com base em avaliação de risco à saúde humana, assim como aos bens a proteger, em cenário de exposição padronizado ou específico;

(...)

XVII - Remediação: uma das ações de intervenção para reabilitação de área contaminada, que consiste em aplicação de técnicas, visando a remoção, contenção ou redução das concentrações de contaminantes;

XVIII - Reabilitação: ações de intervenção realizadas em uma área contaminada visando atingir um risco tolerável, para o uso declarado ou futuro da área;

(...)

(BRASIL, 2009, p.2). 
A Resolução CONAMA n ${ }^{\circ} 420$ traz ainda a implementação pelo IBAMA do Banco de Dados Nacional sobre Áreas Contaminadas, baseando-se em informações fornecidas pelos estados.

Embora a Resolução $n^{\circ}$ 420/2009 tenha trazido essas importantes definições, ainda não havia um consenso sobre a definição de áreas contaminadas no contexto legal. Foi só em 2010, com a lei n ${ }^{\circ}$ 12.305 da Política Nacional de Resíduos Sólidos, que houve uma definição específica, incluindo o importante conceito da área contaminada órfã:

Art. $3^{\circ}$ Para os efeitos desta Lei, entende-se por:

(...)

II - Área contaminada: local onde há contaminação causada pela disposição, regular ou irregular, de quaisquer substâncias ou resíduos;

III - Área órfã contaminada: área contaminada cujos responsáveis pela disposição não sejam identificáveis ou individualizáveis;

(BRASIL, 2010, n. p.)

\subsubsection{A Função Social da Propriedade}

Além das questões ambientais que permeiam o assunto das áreas contaminadas, torna-se importante entender os aspectos sociais do tema. Assim sendo, destaca-se na Constituição Federal de 1988 a questão da função social da propriedade, como estabelecida legalmente no Brasil em seu artigo $5^{\circ}$ :

Art. $5^{\circ}$ Todos são iguais perante a lei, sem distinção de qualquer natureza, garantindo-se aos brasileiros e aos estrangeiros residentes no País a inviolabilidade do direito à vida, à liberdade, à igualdade, à segurança e à propriedade, nos termos seguintes:

(...)

XXIII - a propriedade atenderá a sua função social;(...)

(BRASIL, 1988, n. p.).

Observa-se aqui que a igualdade social se reflete na propriedade, o que vem definido pela lei federal $n^{0} 10.257 / 2001$, que traz instrumentos que permitem à administração local induzir o cumprimento da função social da propriedade, sendo modificado pelo Estatuto da Metrópole, Lei 13.089/2015, que altera a Lei no 10.257, de 10 de julho de 2001. Com isto, por exemplo, há obrigação de um aproveitamento mínimo do terreno, sujeito a penalizações pelo município caso essas obrigações não sejam cumpridas. O poder local pode então estabelecer um IPTU progressivo, com aumentos sucessivos de modo a provocar a obediência da lei, ou, finalmente levando à desapropriação, em caso de ausência de cumprimento da lei. Deve ficar claro ainda, que as áreas contaminadas permeiam toda a discussão sobre a função social da propriedade, pois em geral os terrenos são frequentemente subutilizados, demorando a receber novos usos, dado à dificuldade trazida pela contaminação (SÁNCHEZ, 2001).

\subsection{Legislações e Políticas Estaduais}

Segundo Spínola (2011), São Paulo é o Estado brasileiro com o maior número de áreas contaminadas levantadas (figura 3), em especial na Região Metropolitana de São Paulo. Isto se deve ao crescimento industrial do Estado de São Paulo na década de 1950, muito antes da criação das primeiras normas ambientais que regulariam a emissão de poluentes industriais no meio ambiente, o que desencadeou a formação de passivos ambientais. 


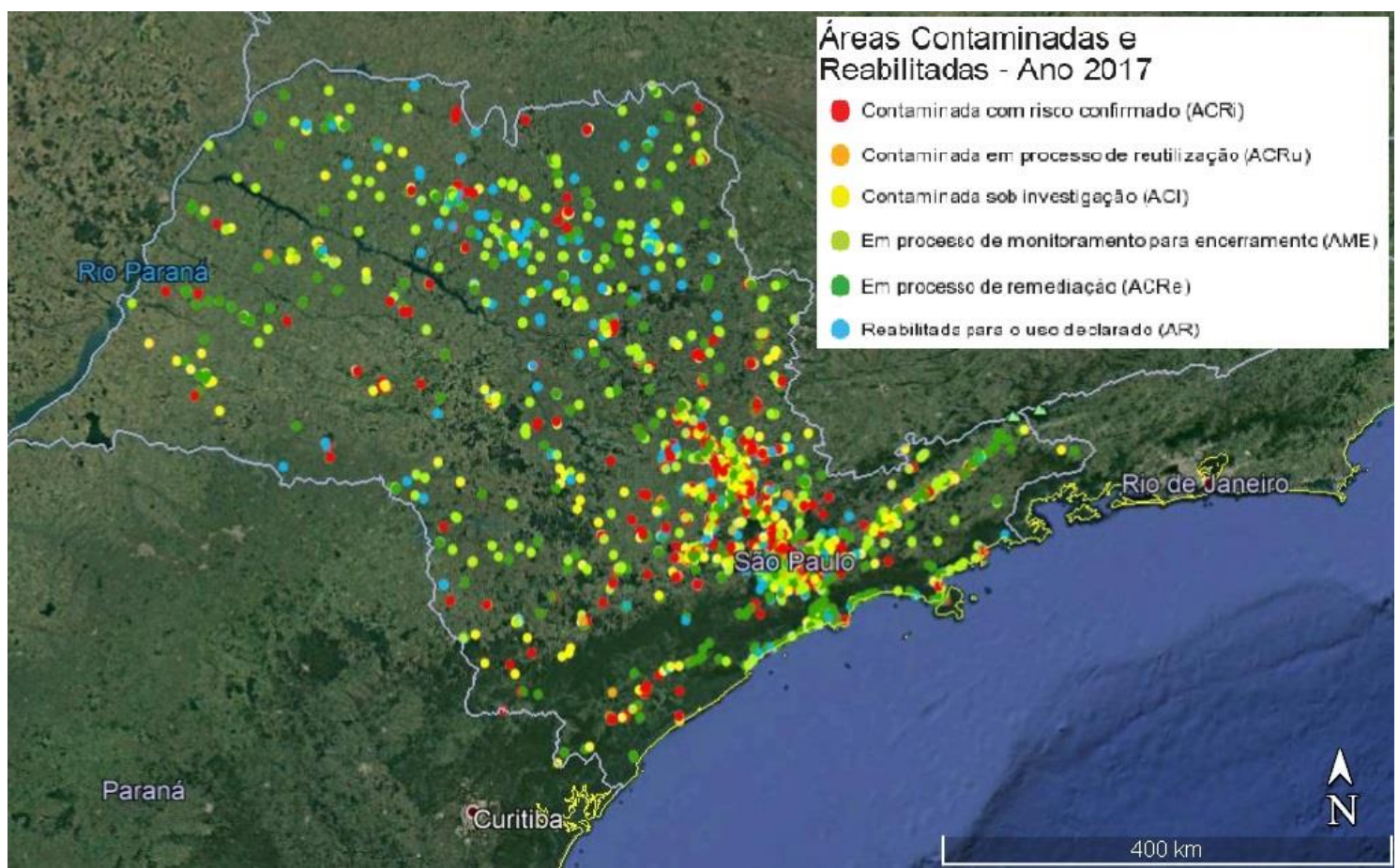

Figura 3: Levantamento das Áreas Contaminadas e Reabilitadas no ano de 2017 no Estado de São Paulo. Fonte: Elaborado pela autora (DA MATA), com base levantamento da CETESB.

Em 1976, criou-se a lei no 997 e o Decreto Estadual nº 8.468, que estabeleceram mecanismos de controle de poluição e licenciamento ambiental a fim de evitar a formação de novos passivos ambientais. Dois anos depois, a lei ${ }^{\circ} 1.817 / 1978$ apresentou o Zoneamento Industrial na Região Metropolitana de São Paulo.

Como apresentado na introdução deste artigo, durante a partir da década de 1970 houve um processo de reestruturação econômica, que no Estado de São Paulo se aliou a um processo de "interiorização" das indústrias, fazendo com que a Região Metropolitana de São Paulo sofresse uma desindustrialização (SPÍNOLA, 2011). Tais processos produziram vazios contaminados por toda Região Metropolitana de São Paulo.

Dada a magnitude do problema, em 1989, o Estado de São Paulo começa a legislar especificamente sobre as áreas contaminadas em sua Constituição Estadual, que as inclui no grande grupo das áreas degradadas, em seu Capítulo IV do Meio Ambiente, dos Recursos Naturais e do Saneamento:

Artigo 193 - O Estado, mediante lei, criará um sistema de administração da qualidade ambiental, proteção, controle e desenvolvimento do meio ambiente e uso adequado dos recursos naturais, para organizar, coordenar e integrar as ações de órgãos e entidades da administração pública direta e indireta, assegurada a participação da coletividade, com o fim de:

(...)

II - Adotar medidas, nas diferentes áreas de ação pública e junto ao setor privado, para manter e promover o equilíbrio ecológico e a melhoria da qualidade ambiental, prevenindo a degradação em todas as suas formas e impedindo ou mitigando impactos ambientais negativos e recuperando o meio ambiente degradado;

(...)

IV - Realizar periodicamente auditorias nos sistemas de controle de poluição e de atividades potencialmente poluidoras;

(...)

XIV - promover medidas judiciais e administrativas de responsabilização dos causadores de poluição ou de degradação ambiental;

(...) 
XX - Controlar e fiscalizar obras, atividades, processos produtivos e empreendimentos que, direta ou indiretamente, possam causar degradação do meio ambiente, adotando medidas preventivas ou corretivas e aplicando as sanções administrativas pertinentes;

(ESTADO DE SÃO PAULO, 1989, n. p.)

Em decorrência da progressiva desindustrialização dos bairros tradicionalmente industrializados, anteriormente definidos na lei de 1978, foram estabelecidas, na década de 1990, as leis $\mathrm{n}^{\circ}$ 9.472/1996 e nº 9.999/1998, que define a admissão de usos não-industriais nas áreas que tenham passado por descaracterização de seu uso predominantemente industrial.

Neste mesmo período, foi criada a Política Estadual de Meio Ambiente (lei no 9.509/1997) que, assim como o Constituição do Estado de São Paulo, ainda não trata especificamente das áreas contaminadas, colocando-as como áreas degradadas. Além disso, apresenta a responsabilidade do Estado, do município e do poluidor para a recuperação dessas áreas. Para tanto, estabelece as seguintes definições:

Artigo $3^{\circ}$ - Para os fins previstos nesta Lei, entende-se por:

(...)

II - degradação da qualidade ambiental: a alteração adversa das características do meio ambiente;

III - poluição: a degradação da qualidade ambiental resultante de atividades que direta ou indiretamente:

a) prejudiquem a saúde, a segurança e o bem-estar da população;

b) criem condições adversas às atividades sociais e econômicas;

c) afetem desfavoravelmente a biota;

d) afetem as condições estéticas ou sanitárias do meio ambiente;

e) lancem matérias ou energia em desacordo com os padrões ambientais estabelecidos; e

f) afetem desfavoravelmente a qualidade de vida;

IV - poluidor: a pessoa física ou jurídica, de direito público ou privado, responsável, direta ou indiretamente, por atividade causadora de degradação ambiental;

(...)

(ESTADO DE SÃO PAULO, 1997, n. p.)

Nota-se que, até então, a abordagem das áreas contaminadas pelo Estado de São Paulo era pouco específica, tratando da questão sempre de forma ampla em conjunto com outros tipos de áreas degradadas. Em 2002, no entanto, o assunto passa a ser tratado com maior especificidade, a partir da Resolução Conjunta SS/SMA nº 1 , entre as Secretarias da Saúde e do Meio Ambiente no Estado de São Paulo. Embora seja um documento bastante breve, destaca a importância de mobilizar ações para a reabilitação de áreas contaminadas de forma específica, assim como definir os órgãos que deverão se responsabilizar sobre as questões das áreas contaminadas no Estado:

Os Secretários de Estado da Saúde e de Meio Ambiente, (...) considerando a existência de áreas contaminadas por substâncias perigosas no Estado de São Paulo; considerando que algumas destas áreas contaminadas podem representar risco significativo à qualidade do meio ambiente e à saúde da população; considerando a necessidade da manutenção de ações contínuas e integradas para efetiva avaliação e intervenção nestas áreas, resolvem:

(...)

Artigo $2^{\circ}$ - Caberá à CETESB, representando a Secretaria de Estado do Meio Ambiente, e ao Centro de Vigilância Sanitária - CVS, pela Secretaria de Estado da Saúde, a coordenação destas ações, devendo estes órgãos definir procedimentos e rotinas comuns para uma atuação mais efetiva e integrada das Secretarias.

Artigo $3^{\circ}$ - Nos procedimentos e rotinas deverão ser consideradas as ações comuns e específicas das Secretarias para avaliação, monitoramento e intervenção em áreas contaminadas (...).

(SECRETARIA DO MEIO AMBIENTE, 2002, p.1) 
A partir desta Resolução, a Companhia Ambiental do Estado de São Paulo (CETESB), fundada em 1968, fica responsável por monitorar as áreas contaminadas e propor ações para sua remediação e reabilitação. Ainda na década de 1990, a CETESB estabeleceu uma parceria com o governo da Alemanha para troca de informações e capacitar equipes envolvidas no gerenciamento das áreas de áreas contaminadas. Tal parceria gerou diversos frutos, como o "Manual de Gerenciamento de Áreas Contaminadas" de 1999, que apresenta diversos procedimentos para recuperação de tais terrenos.

Em 2002, a CETESB emitiu o Decreto $\mathrm{n}^{\circ} 47.400 / 2002$, que visa regulamentar a Política Estadual de Meio Ambiente de 1997, aqui já citada. Embora ainda não mencione especificamente as áreas contaminadas, o Decreto ${ }^{\circ}$ 47.400:

(...) estabelece prazos de validade para cada modalidade de licenciamento ambiental e condições para sua renovação, estabelece prazo de análise dos requerimentos e licenciamento ambiental, institui procedimento obrigatório de notificação de suspensão ou encerramento de atividade, e o recolhimento de valor referente ao preço de análise.

(ESTADO DE SÃO PAULO, 2002, p. 1)

Outro resultado da parceria entre CETESB e governo alemão foi o "Guia para a Avaliação do Potencial de Contaminação em Imóveis", que visa orientar empreendedores por meio de recomendações para a identificação de possível contaminação em imóveis.

Finalmente, em 2006 é emitida uma lei estadual que traga uma definição específica para áreas contaminadas, com a lei $\mathrm{n}^{\mathbf{0}}$ 12.300/2006 que estabelece a Política Estadual de Resíduos Sólidos. Dentre as muitas definições, vale destacar:

Artigo $5^{\circ}$ - Para os efeitos desta lei, consideram-se:

(...)

IX - área contaminada: área, terreno, local, instalação, edificação ou benfeitoria que contém quantidades ou concentrações de matéria em condições que causem ou possam causar danos à saúde humana, ao meio ambiente e a outro bem a proteger;

$X$ - área degradada: área, terreno, local, instalação, edificação ou benfeitoria que por ação humana teve as suas características ambientais deterioradas;

XI - remediação de área contaminada: adoção de medidas para a eliminação ou redução dos riscos em níveis aceitáveis para o uso declarado;

(...)

XVII - reutilização: prática ou técnica na qual os resíduos podem ser usados na forma em que se encontram sem necessidade de tratamento para alterar as suas características físico-químicas;

(...)

(ESTADO DE SÃO PAUULO, 2006, n. p.)

Além disso, tal Política apresenta a necessidade de estabelecer parcerias Público-Privadas para a reabilitação das áreas contaminadas, assim como o aporte de recursos para tanto.

Dando continuação às ações que facilitem a remediação e reabilitação das áreas contaminadas, a CETESB emitiu a Decisão 103/2007/C/E, que descreve, da maneira mais detalhada até então, os procedimentos para a remediação dos terrenos. Esta Decisão da CETESB traz também suas próprias definições, incluindo a definição de Área Reabilitada para Uso Declarado:

Área contaminada (AC): área, terreno, local, instalação, edificação ou benfeitoria, anteriormente classificada como área contaminada sob investigação (AI) na qual, após a realização de avaliação de risco, foram observadas quantidades ou concentrações de matéria em condições que causem ou possam causar danos à saúde humana. (...)

(...) 
Área reabilitada para o uso declarado (AR): área, terreno, local, instalação, edificação ou benfeitoria, anteriormente classificada como área em processo de monitoramento para reabilitação (AMR) que, após a realização do monitoramento para encerramento, for considerada apta para o uso declarado.

(CETESB, 2007, p.6)

Essa Decisão também criou o Grupo Gestor de Áreas Críticas (GAC), uma equipe para tratar com mais profundidade sobre terrenos que, por sua contaminação, gerem inquietação na população e necessitem de procedimentos diferenciados. Segundo Spínola (2011), embora não seja o objetivo principal do grupo, a criação dessa equipe possibilitou que a remediação de terrenos críticos, já tão burocrática e demorada devido à gravidade da contaminação, recebesse maior atenção e permitisse que o processo de aprovação fosse mais facilitado. Consequentemente, o GAC torna a reabilitação dessas áreas menos trabalhosa e mais atraente para empreendedores.

Aprofundando ainda mais o assunto, foi emitida a lei $\mathrm{n}^{\circ} 13.577 / 2009$, que traz diversos instrumentos, desde o licenciamento, plano de desativação e cadastro das áreas contaminadas, até incentivos ficais, tributários e fundos para a remediação. Destaca-se aqui a definição de remediação trazida pela lei:

Remediação de área contaminada: adoção de medidas para a eliminação ou redução dos riscos em níveis aceitáveis para o uso declarado;

(ESTADO DE SÃO PAULO, 2009, n. p.)

Também cria o Fundo Estadual para a Prevenção e Remediação de Áreas Contaminadas (FEPRAC) vinculado à Secretaria do Meio Ambiente, que visa o incentivo à identificação e remediação de áreas contaminadas:

Artigo 31 - Constituem receitas do FEPRAC:

I - dotações ou créditos específicos, consignados no orçamento do Estado;

II - transferências de outros fundos estaduais ou de suas subcontas, cujos recursos se destinem à execução de projetos, planos, programas, atividades e ações relacionados com a prevenção e o controle da poluição, de interesse comum;

III - transferência da União, dos Estados e dos Municípios para a execução de planos, programas, atividades e ações de interesse do controle, preservação e melhoria das condições do meio ambiente do Estado;

(...)

Artigo 32 - Os recursos de que trata o artigo 31, serão aplicados em operações financeiras destinadas a apoiar e a incentivar a execução de ações relacionadas com a identificação e remediação de áreas contaminadas.

$\S 1^{\circ}$ - Os recursos do FEPRAC poderão ser aplicados a fundo perdido, quando o tomador for o Estado e os recursos forem utilizados visando à intervenção em área contaminada, para remoção de perigo iminente à saúde pública.

$\S 2^{\circ}$ - O Estado deverá ser ressarcido, pelo responsável legal pela área contaminada das despesas decorrentes da identificação e remediação de áreas contaminadas de acordo com o estabelecido no $\S 1^{\circ}$ deste artigo.

(ESTADO DE SÃO PAULO, 2009, n. p.)

Em 2010, assim como na parceria anterior com o governo alemão, a CETESB buscou maior capacitação dos agentes envolvidos na reabilitação de áreas contaminadas traçando parceria com as universidades canadenses de Guelph e Waterloo.

Recentemente, a Secretaria de Meio Ambiente do Estado publicou a Resolução SMA no 11 de fevereiro de 2017 que, embora seja estadual, trata especificamente da cidade de São Paulo: estabelece regiões prioritárias para realização de avaliação preliminar e investigação confirmatória 
(figura 4), obrigando o empreendedor a avaliar a existência de contaminação em terrenos no município de São Paulo.

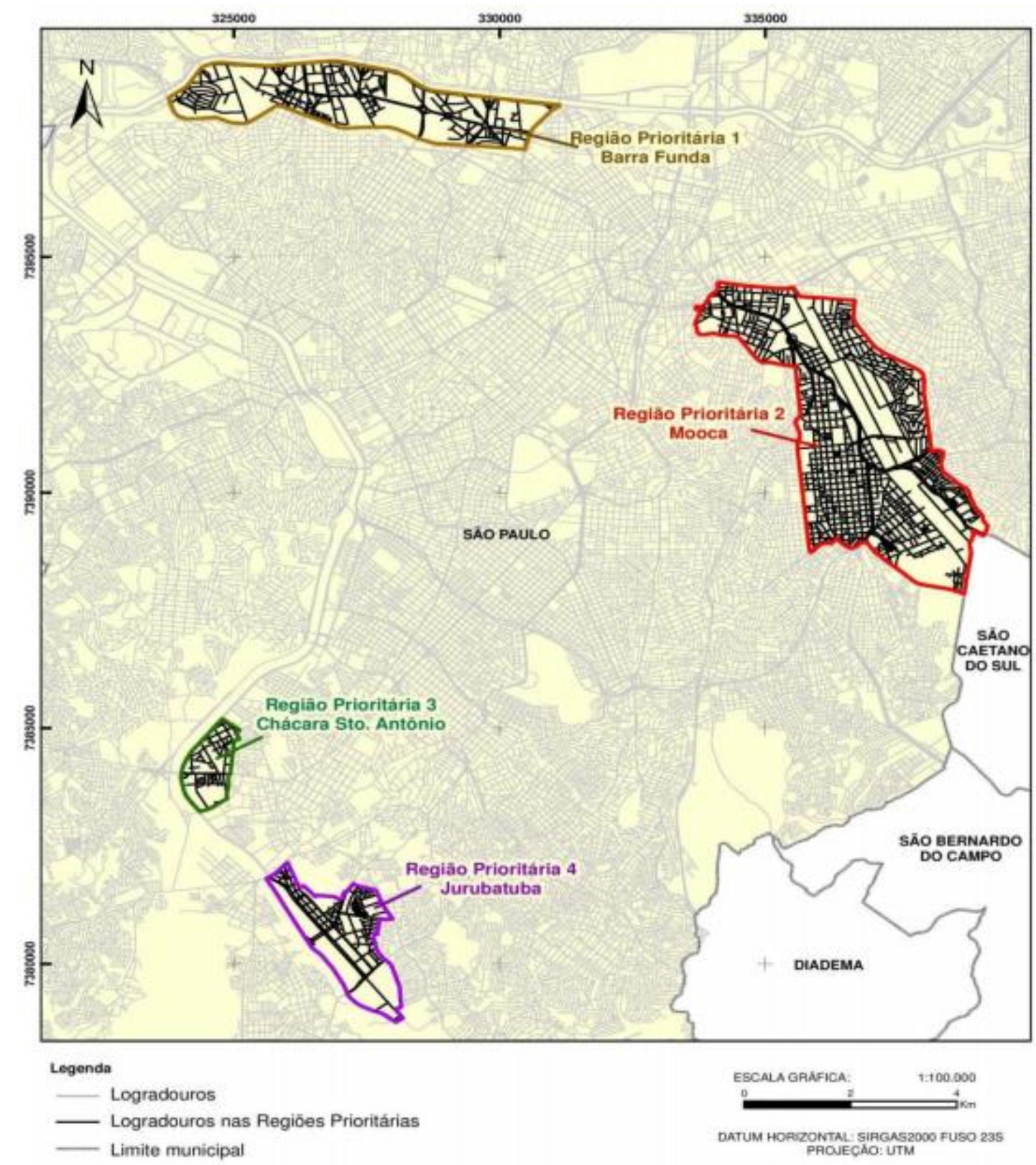

Figura 4: Regiões Prioritárias para Realização de Avaliação Preliminar e Investigação Confirmatória. Fonte: Resolução SMA no 11.

Ainda, em 2018, a partir de parceria da Secovi com o Instituto de Pesquisa Tecnológicas do Estado de São Paulo (IPT) lançou um manual direcionado a investidores imobiliários, intitulado "A Produção e a Reabilitação de Áreas Contaminadas" que, embora não seja de teor jurídico, é de grande ajuda para a reabilitação de áreas contaminadas. Segundo Manna et al (2018), o documento:

(...) tem como objetivo oferecer suporte para que a decisão de se empreender em área que envolva contaminação no solo ou em água subterrânea seja realizada com mais informação e, portanto, com maior segurança e menor risco.

(MANNA et al, 2018, p.5) 
Spínola (2011), destaca a importância da atual estadual na reabilitação de áreas contaminadas, mas sobretudo, a ação municipal, como será tratado a seguir.

\subsection{Legislações e Políticas Municipais}

Dentro do Estado de São Paulo, a capital se destaca por ser o único município que apresenta uma equipe completa e atuante na gestão de áreas contaminadas (SPÍNOLA, 2011). Em 1990, a Secretaria Municipal do Meio Ambiente (SVMA) foi criada, objetivando coordenar ações de cunho ambiental.

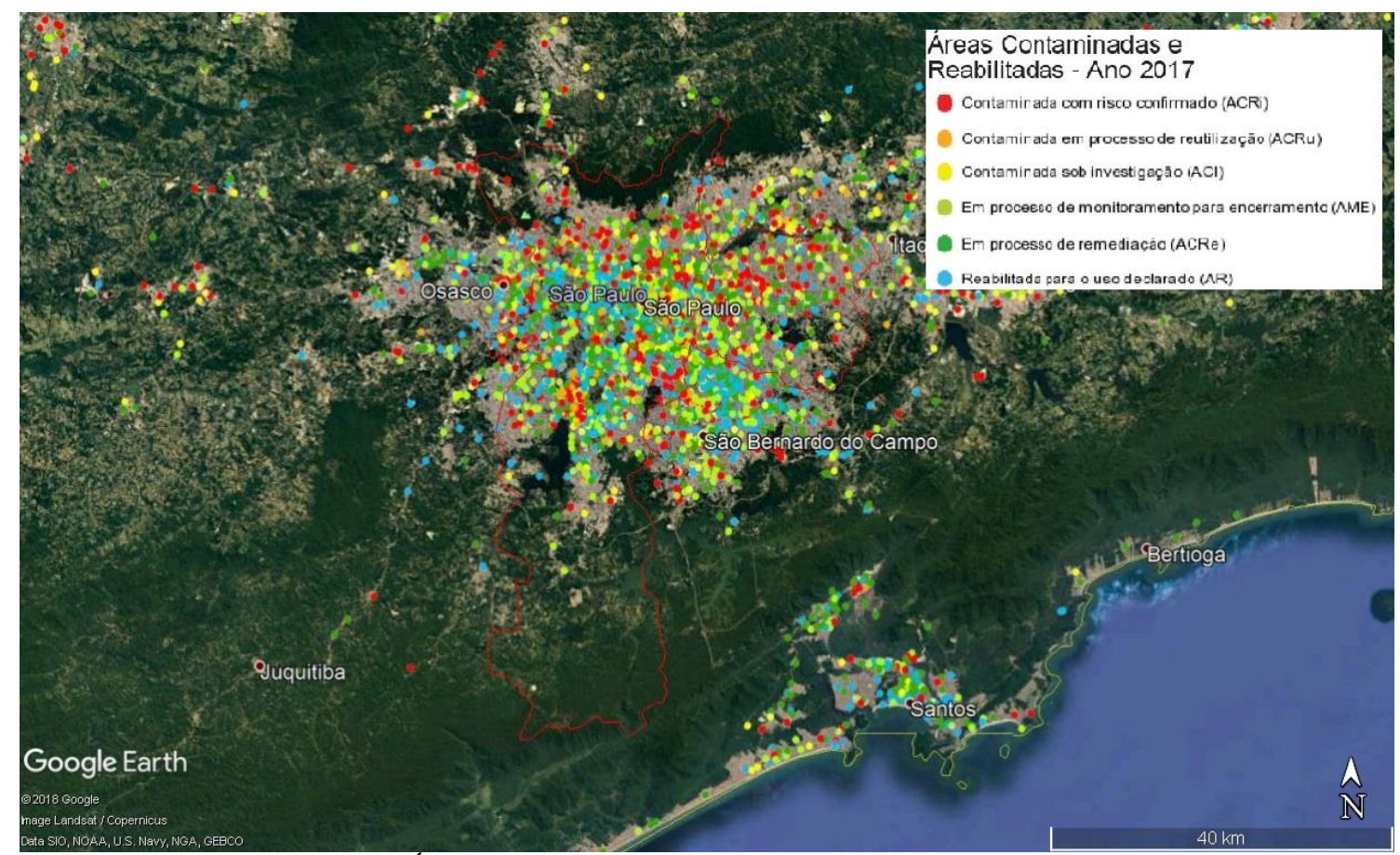

Figura 5: Levantamento das Áreas Contaminadas e Reabilitadas no ano de 2017 na cidade de São Paulo. Fonte: Elaborado pela autora (DA MATA), com base levantamento da CETESB.

Segundo Manna et al (2018), desde a Lei Estadual 9.999/1998 que passa a permitir usos diferentes em regiões até então predominantemente industrial (ZUPI), a cidade de São Paulo passou a converter imóveis industriais para usos residenciais e comerciais.

Além da SVMA, outros órgãos passaram a integrar o sistema municipal de meio ambiente: em 2001, a partir da lei $\mathrm{n}^{\mathrm{o}}$ 13.155, foi estabelecido o Fundo Especial do Meio Ambiente e Desenvolvimento Sustentável (FEMA) que mobiliza recursos para planos, programas e projetos de cunho ambiental, e o Conselho do Fundo Especial do Meio Ambiente e Desenvolvimento Sustentável (CONFEMA), que define as condições operacionais do FEMA.

Para concorrer aos valores, as Organizações da Sociedade Civil de Interesse Público (OSCIP) e Organizações Não Governamentais (ONG) brasileiras e sem fins lucrativos concorrem por meio de editais de chamamento. Nesses editais, devem apresentar planos, programas ou projetos com atendimento às diretrizes, prioridades e programas estabelecidos anualmente pelo Conselho Municipal de Meio Ambiente e Desenvolvimento Sustentável - CADES. Os editais são publicados em jornais e disponibilizados no site da SVMA.

(PREFEITURA DE SÃO PAULO, 2017, n. p.)

Em 2002, foi criado junto à SVMA o Grupo Técnico Permanente de Áreas Contaminadas (GTAC), a fim de promover a gestão de tais terrenos no município, por meio do cadastro das áreas 
contaminadas integrado às informações da CETESB, além de propor ações de controle e remediação de tais terrenos. No mesmo ano, foi criada a primeira legislação municipal específica sobre o assunto: Decreto $\mathrm{n}^{\circ} 42.319$, que dispõe de diretrizes e procedimentos para o gerenciamento de áreas contaminadas ou suspeitas de contaminação. Ainda adiciona a responsabilidade das subprefeituras em fiscalizar seus terrenos contaminados ou com suspeita de contaminação.

Como resultado da parceria Brasil-Alemanha, entre os anos de 2002 e 2004 foi desenvolvido o Projeto de Gestão Ambiental Urbana (ProGAU), que desenvolveu o "Modelo de Gerenciamento de Recuperação de Áreas Urbanas Degradadas por Contaminação", a fim de estimular a SVMA a adotar uma abordagem proativa sobre a reabilitação dessas áreas vazias contaminadas. No ano seguinte, firmou-se também o Termo de Cooperação entre a CETESB e a cidade de São Paulo a fim de implantar um sistema integrado para gerenciamento de áreas contaminadas, o que iniciou uma ação conjunta para um maior levantamento e monitoramento dos terrenos em condição de contaminação no município (SPÍNOLA, 2011).

Em 2010, mais um passo foi dado em direção a organização dos levantamentos das áreas contaminadas: a partir da lei $\mathrm{n}^{\mathrm{o}} 15.098$, o poder executivo municipal é obrigado a publicar o "Relatório das Áreas Contaminadas", gerado a partir do Sistema de Informação de Gerenciamento de Áreas Contaminadas (SIGAC), banco de dados que disponibiliza informações sobre áreas comprovadamente ou potencialmente contaminadas (SPÍNOLA, 2011).

\section{MÉTODOS}

Partindo do método de análise apresentado por Adams, de Sousa e Tiesdell (2010), pretende-se produzir compreensão da evolução da legislação para reabilitação de áreas contaminadas no Brasil, no Estado de São Paulo e na capital. Segundo Adams, de Sousa e Tiesdell (2010), a maturidade de legislações e políticas públicas pode ser estudada por meio de uma estrutura de três estágios.

O primeiro estágio se refere ao reconhecimento da total dimensão da questão das áreas contaminadas pelos envolvidos na criação das políticas urbanas. Os autores destacam que isso pode começar, por exemplo, pelas das definições da lei, pois refletem as dificuldades das políticas em determinado tempo e escala. Outro fator importante apontado pelos autores para esse estágio é o levantamento das áreas em inventário, preferencialmente disponível para consulta.

O segundo estágio é a mudança de paradigma: problema urbano para oportunidade de desenvolvimento. Segundo Adams, de Sousa e Tiesdell (2010), esta mudança de visão só é possível se houver um contexto atrativo para o empreendedor pois, segundo os autores, o sucesso das políticas de reabilitação de áreas contaminadas depende do envolvimento do setor privado e investidores.

Isto nos leva ao terceiro estágio apontado por Adams, de Sousa e Tiesdell (2010), que trata do engajamento dos agentes privados. Isto é, as legislações em prol da reabilitação de áreas contaminadas devem visar a mobilização de investimentos privados de tal maneira a atingir objetivos públicos.

\section{RESULTADOS E DISCUSSÕES}

Por meio da estrutura de estágios apresentada na metodologia, pode-se destacar algumas características das legislações em prol da reabilitação de áreas contaminadas. Sobre o primeiro estágio, pode-se dizer que desde as primeiras legislações acerca do assunto já apresentavam a tentativa de definir o que são as áreas contaminadas, o que se entende por remediação e por reabilitação. No entanto, como apontado por Spínola (2011), algumas definições são conflitantes: enquanto as legislações federais (Política Nacional do Meio Ambiente e a Constituição de 1988) obriguem o poluidor a remediar o terreno até concentrações de contaminantes anteriores à 
contaminação, o Estado de São Paulo segue uma tendência mundial de permitir a remediação até níveis adequados para um uso declarado. Segundo Spínola, a flexibilização da lei, permitindo avaliação de risco para determinados usos declarados, pode fazer com que o custo de remediação das áreas contaminadas seja mais baixo, facilitando o processo de reabilitação. No entanto, a contradição entre definições de diferentes escalas pode comprometer o processo, como apontado por Adams, de Sousa e Tiesdell (2010).

Ainda sobre o primeiro estágio, nota-se um esforço nas três escalas para o levantamento das áreas contaminadas: seja por meio do Banco de Dados Nacional sobre Áreas Contaminadas estabelecido pela CONAMA em 2003, seja pelos cadastros das áreas contaminadas da CETESB do Grupo Técnico Permanente de Áreas Contaminadas da cidade de São Paulo.

Sobre a mudança de abordagem adotada no segundo estágio da metodologia, pode-se destacar o manual da parceria entre Secovi e IPT, lançado esse ano (2018) que já trata dessa mudança de paradigma. Porém, nota-se que as legislações ainda não abordam a questão das áreas contaminadas de forma positiva para induzir sua reabilitação, mas sim de maneira técnica, impondo responsabilidades aos poluidores e proprietários.

Finalmente, sobre o estágio de engajamento dos agentes privados, a maioria das leis apresentadas trazem apenas obrigações ao proprietário, deixando que o fator de decisão de empreender em uma área contaminada seja motivado basicamente pela boa localização, pelas dimensões do terreno e pela boa oferta de infraestrutura nas proximidades do terreno. Segundo Adams, de Sousa e Tiesdell (2010), tais fatores podem ser insuficientes para atrair o alto investimento necessário para a remediação de áreas contaminadas.

Segundo Manna et al (2018), existem alguns incentivos financeiros para empreendimentos em áreas contaminadas, como algumas medidas que favorecem a obtenção de crédito pelo setor imobiliário, como por exemplo o normativo $n^{\circ}$ 14/2.014, emitido pela Federação Brasileira de Bancos (FEBRABAN), que visa estimular políticas de responsabilidade socioambiental. No entanto, não se considera que tais ações sejam suficientes para estimular a escolha das áreas contaminadas para novos empreendimentos.

\section{CONSIDERAÇÕES FINAIS}

O Estado de São Paulo tem tomado a dianteira dentre os estados brasileiros na solução de áreas contaminadas. No entanto, existe muito a ser feito para atingir resultados numéricos e de qualidade como obtidos em outros países onde as legislações para reabilitação de áreas contaminadas estão mais maduras, como Alemanha, Estados Unidos e Canadá. A partir da estrutura de três estágios, percebe-se que ainda falta para as legislações brasileiras, paulistas e paulistanas não só impor restrições ao uso das áreas contaminadas, mas também criar um ambiente propício para ação do mercado imobiliário a favor dos objetivos públicos.

\section{REFERÊNCIAS}

ADAMS, David; DE SOUSA, Christopher; TIESDELL, Steven. Brownfield Development: A Comparison of North American and British Approaches. Urban Studies, Internacional, 47(1) 75104, jan. 2010.

BRASIL. Constituição da República Federativa do Brasil de 1988. Disponível em: < http://www.planalto.gov.br/ccivil_03/Constituicao/Constituicao.htm >. Acesso em 07 de setembro de 2018.

BRASIL. Decreto $\mathbf{n}^{\circ}$ 99.274, de 06 de junho de 1990 . Disponível em <http://www.planalto.gov.br/ccivil_03/decreto/antigos/d99274.htm>. Acesso em 07 de setembro de 2018. 
BRASIL. Lei $\mathbf{n}^{\circ} \mathbf{6 . 9 3 8}$, de 31 de agosto de 1981. Dispõe sobre a Política Nacional do Meio Ambiente Disponível em: <http://www.planalto.gov.br/ccivil_03/Leis/L6938.htm>. Acesso em 07 de setembro de 2018.

BRASIL. Lei $\mathbf{n}^{\circ} \mathbf{9 . 9 8 5}$, de 18 de julho de 2000. Disponível em <http://www.planalto.gov.br/ccivil/leis/L9985.htm>. Acesso em 07 de setembro de 2018.

BRASIL. Lei $\mathbf{n}^{\circ} \mathbf{1 0 . 2 5 7}$, de 10 de julho de 2001. Disponível em <http://www.planalto.gov.br/ccivil_03/Leis/LEIS_2001/L10257.htm>. Acesso em 07 de setembro de 2018.

BRASIL. Lei $\mathbf{n}^{\circ} \mathbf{1 0 . 4 0 6}$, de 10 de janeiro de 2001. Disponível em <http://www.planalto.gov.br/ccivil/leis/2002/L10406.htm>. Acesso em 07 de setembro de 2018.

BRASIL. Lei $\mathbf{n}^{\circ}$ 12.305, de 02 de agosto de 2010. Institui a Política Nacional de Resíduos Sólidos, altera a Lei no 9.605, de 12 de fevereiro de 1998 e dá outras providências. Disponível em: <http://www.planalto.gov.br/ccivil_03/_ato2007-2010/2010/lei/112305.htm>. Acesso em 07 de setembro de 2018.

CAIXA ECONÔMICA FEDERAL. Avaliação Ambiental de Terrenos com Potencial de Contaminação. Disponível em < http://www.caixa.gov.br/Downloads/desenvolvimento-urbanogestao-ambiental/GuiaCAIXA_web.pdf > Acesso em 08/02/2017

CAMPOS NETO, Candido Malta; SOMEKH, Nadia. Desenvolvimento Local e Projetos Urbanos. Disponível em < http://www.vitruvius.com.br/revistas/read/arquitextos/05.059/470 > Acesso em 03 de maio de 2017.

CETESB - COMPANHIA AMBIENTAL DO ESTADO DE SÃO PAULO. Decisão de Diretoria $\mathbf{n}^{\circ} \mathbf{1 0 3 / 2 0 0 7 / C / E}$, de 22 de junho de 2007. Diário Oficial do Estado de São Paulo, São Paulo, 27 jun. 2007. Seção I, p. 34-39.

CETESB - COMPANHIA AMBIENTAL DO ESTADO DE SÃO PAULO. Guia para avaliação do potencial de contaminação em Imóveis. São Paulo: CETESB/GTZ, 2003.

CETESB - COMPANHIA AMBIENTAL DO ESTADO DE SÃO PAULO. Manual de Gerenciamento de Áreas Contaminadas. São Paulo: CETESB/GTZ, 1999.

CETESB. Decreto $\mathbf{4 7 . 4 0 0}$ de 4 de dezembro de 2002. Disponível em < https://www.cetesb.sp.gov.br/Institucional/documentos/dec47400.pdf > acesso em 04 de outubro de 2018.

CONAMA - CONSELHO NACIONAL DO MEIO AMBIENTE. Resolução n ${ }^{\circ} \mathbf{2 7 3}$, de 29 de novembro de 2000.2 Disponível em: <http://www.mma.gov.br/port/conama/res/res00/res27300.html >. Acesso em 07 de setembro de 2018.

CONAMA - CONSELHO NACIONAL DO MEIO AMBIENTE. Resolução $\mathbf{n}^{\circ} \mathbf{4 2 0}$, de 28 de dezembro de 2009. Disponível em $<$ http://www.mma.gov.br/port/conama/legiabre.cfm?codlegi=620>. Acesso em 07 de setembro de 2018.

MANNA, Eduardo Della; ARAUJO, Marcela Maciel de; MELLO JUNIOR, Rivaldo França de (Org.) A produção imobiliária e a reabilitação de áreas contaminadas: contratação de serviços, responsabilidades legais e viabilidade de empreendimentos. São Paulo: IPT: SECOVI, 2018.

SÁNCHEZ, Luís Enrique. Desengenharia: O Passivo Ambiental na Desativação de Empreendimentos Industriais. Editora da Universidade de São Paulo, São Paulo. 2001. Disponível em $\quad$ https://books.google.com.br/books?id=SQM_xAnKtpEC\&pg=RA2- 
PA7\&lpg=RA2PA7\&dq=tombamentos + sao + caetano + do + sul + matarazzo $\&$ source $=$ bl\&ots $=a Z M z$ 4otiCR\&sig=NNdd2dGwoKFKj18EH7q9D7X_ehs\&hl=en\&sa=X\&ved=0ahUKEwjn0Jqx66PS AhXLgZAKHayfDVkQ6AEIWjAJ\#v=onepage $\& q \& f=$ false $>$ Acesso em 22 de fevereiro de 2017.

SÁNCHEZ, Luís Enrique. Revitalização de áreas contaminadas. In: Moeri, E.; Coelho, R.; Marker, A. (orgs.), Remediação e Revitalização de Áreas Contaminadas: Aspectos Técnicos, Legais e Financeiros. São Paulo: Signus Editora, p. 79-90, 2004.

SÃO PAUlO (cidade). FEMA - Fundo Especial do Meio Ambiente e Desenvolvimento Sustentável. 19 de dezembro de 2017. Disponível em < https://www.prefeitura.sp.gov.br/cidade/secretarias/meio_ambiente/confema/index.php?p=3299 $>$ acesso em 07 de setembro de 2018.

SÃO PAUlO (cidade). Lei $\mathbf{n}^{\mathbf{0}}$ 13.155, de 29 de junho de 2001. Disponível em <http://camaramunicipalsp.qaplaweb.com.br/iah/fulltext/leis/L13155.pdf〉. Acesso em 08 de setembro de 2018.

SÃO PAUlO (cidade). Decreto $\mathbf{n}^{\circ}$ 42.319, de 21 de agosto de 2002. Disponível em <http://camaramunicipalsp.qaplaweb.com.br/iah/fulltext/decretos/D42319.pdf>. Acesso em $08 \mathrm{de}$ setembro de 2018.

SÃO PAULO (cidade). Decreto $\mathbf{n}^{\mathbf{0}}$ 51.436, de 26 de abril de 2010. Disponível em $<$ http://camaramunicipalsp.qaplaweb.com.br/iah/fulltext/decretos/D51436.pdf >. Acesso em $08 \mathrm{de}$ setembro de 2018.

SÃO PAUlO (Estado). Constituição do Estado de São Paulo. Disponível em < http://www.pge.sp.gov.br/centrodeestudos/bibliotecavirtual/dh/volume\%20i/constituicao\%20esta dual.htm> Acesso em 07 de setembro de 2018.

SÃO PAUlO (Estado). Decreto $\mathbf{n}^{\circ} \mathbf{8 . 4 6 8}$, de 08 de setembro de 1976. Disponível em http://www.cetesb.sp.gov.br/Institucional/documentos/Dec8468.pdf. Acesso em 07 de setembro de 2018.

SÃO PAUlO (Estado). Lei $\mathbf{n}^{\circ} \mathbf{1 . 8 1 7}$, de 27 de outubro de 1978. Disponível em < http://licenciamento.cetesb.sp.gov.br/legislacao/estadual/leis/1978_Lei_Est_1817.pdf > acesso em 07 de setembro de 2018.

SÃO PAUlO (Estado). Lei $n^{\circ}$ 12.300, de 16 de março de 2006. Disponível em < https://www.al.sp.gov.br/repositorio/legislacao/lei/2006/lei-12300-16.03.2006.html > acesso em 07 de setembro de 2017.

SÃO PAUlO (Estado). Lei $\mathbf{n}^{\mathbf{0}}$ 13.577, de 8 de julho de 2009. Disponível em < https://www.al.sp.gov.br/repositorio/legislacao/lei/2009/lei-13577-08.07.2009.html>. Acesso em 07 de setembro de 2017.

SÃO PAUlO (Estado). Lei $n^{0}$ 9.472, de 30 de dezembro de 1996. Disponível em <http://www.al.sp.gov.br/repositorio/legislacao/lei/1996/lei\%20n.9.472,\%20de\%2030.12.1996.h tm> acesso em 07 de setembro de 2018.

SÃO PAUlO (Estado). Lei $\mathbf{n}^{\mathbf{0}}$ 9.999, de 9 de junho de 1998. Disponível em <http://www.al.sp.gov.br/repositorio/legislacao/lei/1998/lei\%20n.9.999,\%20de\%2009.06.1998.h tm> Acesso em 07 de setembro de 2018.

SÃO PAUlO (Estado). Lei $\mathbf{n}^{\mathbf{0}}$ 9.509, de 20 de março de 1997. Disponível em < https://www.al.sp.gov.br/repositorio/legislacao/lei/1997/lei-9509-20.03.1997.html>. Acesso em 07 de setembro de 2018. 
SÃO PAULO (Estado). Resolução Conjunta SS/SMA 1, de 6 de junho de 2002. Disponível em $<$ http://www.ipef.br/legislacao/bdlegislacao/detalhes.asp?Id=12865>. Acesso em 07 de setembro de 2018.

SÃO PAULO (Estado). Resolução SMA 11, de 8 de fevereiro de 2017. Disponível em < http://arquivos.ambiente.sp.gov.br/legislacao/2017/02/resolucao-sma-011-2017-definicao-dasregioes-prioritarias-e-identificacao-das-areas-contaminadas.pdf $>$. Acesso em 08 de setembro de 2018.

SPÍNOLA, Ana Luiza Silva. Inserção das Áreas Contaminas na Gestão Municipal: desafio e tendências. 2011. Tese (Doutorado em Saúde Pública) - Faculdade de Saúde Pública da USP, São Paulo, 2011.

UNITED NATIONS. Our Common Future, Chapter 1: A Threatened Future. Disponível em <http://www.un-documents.net/ocf-01.htm> Acesso em 1 de maio de 2014. 